\title{
Effect of Process Condition on Tensile Properties of Carbon Fiber
}

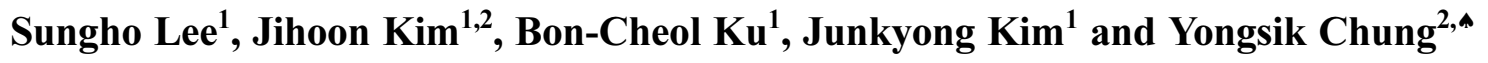 \\ ${ }^{1}$ Institute of Advanced Composite Materials, Korea Institute of Science and Technology, Jeonbuk, 565-902, Korea \\ ${ }^{2}$ Department of Textile Engineering, Chonbuk National University, Jeonju 561-756, Korea \\ ‘e-mail: psdcolor@chonbuk.ac.kr \\ (Received January 6, 2011; Accepted February 21, 2011)
}

\begin{abstract}
For polyacrylonitrile (PAN) based carbon fiber (CF) process, we developed a lab scale wet spinning line and a continuous tailor-made stabilization system with ten columns for controlling temperature profile. PAN precursor was spun with a different spinning rate. PAN spun fibers were stabilized with a total duration of 45 to $110 \mathrm{~min}$ at a given temperature profile. Furthermore, a stabilization temperature profile was varied with the last column temperature from 230 to $275^{\circ} \mathrm{C}$. Stabilized fibers were carbonized in nitrogen atmosphere at $1200^{\circ} \mathrm{C}$ in a furnace. Morphologies of spun and CFs were observed using optical and scanning electron microscopy, respectively. Tensile properties of resulting CFs were measured. The results revealed that process conditions such as spinning rate, stabilization time, and temperature profile affect microstructure and tensile properties of CFs significantly.
\end{abstract}

Keywords : Polyacrylonitrile, Carbon fiber, Tensile properties

\section{Introduction}

To produce polyacrylonitrile (PAN) based carbon fibers $(\mathrm{CFs})$, three stages are required: wet spinning, stabilization, and carbonization. Wet spinning of PAN solution is complicated process, which involves rheological and diffusional phenomena [1-3]. Solvent in PAN solution diffuses out into coagulation bath when PAN solution containing $80-90 \%$ of solvent come out through spinneret into coagulation bath with solvent/water mixture. Consequently, PAN solution is solidified, and fibers are formed. Therefore, PAN concentration and solvent diffusion rate should be controlled to obtain proper solid spun fibers. Technical parameters for solvent diffusion rate are solvent ratio in coagulation bath, temperature of solvent/water mixture, and residence time of fibers. In a wet spinning process, an extraction of solvent was took place in washing baths, steam drawing, and winding. These make wet spinning of PAN solution more complicated.

Stabilization of PAN is performed by heating from 200 to $300^{\circ} \mathrm{C}$ in air under tension, leading to cyclization, dehydrogenation, and oxidation. PAN molecules are cyclized to transform into a non-meltable ladder structure, which is critical to avoid melting during carbonization [4]. It is known that nitrile groups in homo PAN are initiated thermally through a free radical mechanism, leading to cyclized network of hexagonal carbon-nitrogen rings [5]. Furthermore, the nitrile groups in PAN with a large dipole provide high cohesive energy density and chain stiffness, which result in excellent tensile strength [6]. Stabilization is one of the most important factors to determine mechanical strength of PAN based CFs. Fitzer et al. [4] reported optimization of stabilization for PAN fibers and effect of carbonization of resulting stabilized fibers on tensile strength.

In this study, an effect of wet spinning and stabilization on tensile properties of PAN based CFs was reported. A lab scale wet spinning and continuous tailor-made stabilization systems were developed. Wet spun fibers were prepared and further stabilized with a various total residence time and temperature profile. Carbonization was performed for investigating tensile properties of $\mathrm{CFs}$.

\section{Experimental}

Commercial itaconic acid-modified PAN fibers were obtained from Sinosteel Jilin Carbon Co. Ltd. (Jilin, China). From nuclear magnetic resonance analysis, as-received fibers contain $\sim 1 \mathrm{wt} \%$ of itaconic acid. Molecular weight of as-received fibers was found to be $\sim 140000 \mathrm{~g} / \mathrm{cm}^{-1}$ by HLC8320GPC (TOSOH, Japan). PAN fibers were dissolved in dimethyl sulfoxide (DMSO) to prepare a dope (DMSO: PAN=82:18). A lab scale spinning line was developed (Fig. 1). A spinneret with one hundred fifty holes was mounted for wet spinning at $20^{\circ} \mathrm{C}$. The diameter of each hole was $0.1 \mathrm{~mm}$. A wet spinning line had four baths: one coagulation bath and three washing baths. The coagulation bath contained $\mathrm{DMSO} /$ distillated water $(=5: 5)$ mixture at $20^{\circ} \mathrm{C}$, and three washing baths were operated with distillated boiling water. After spinning, fibers were dried in a 


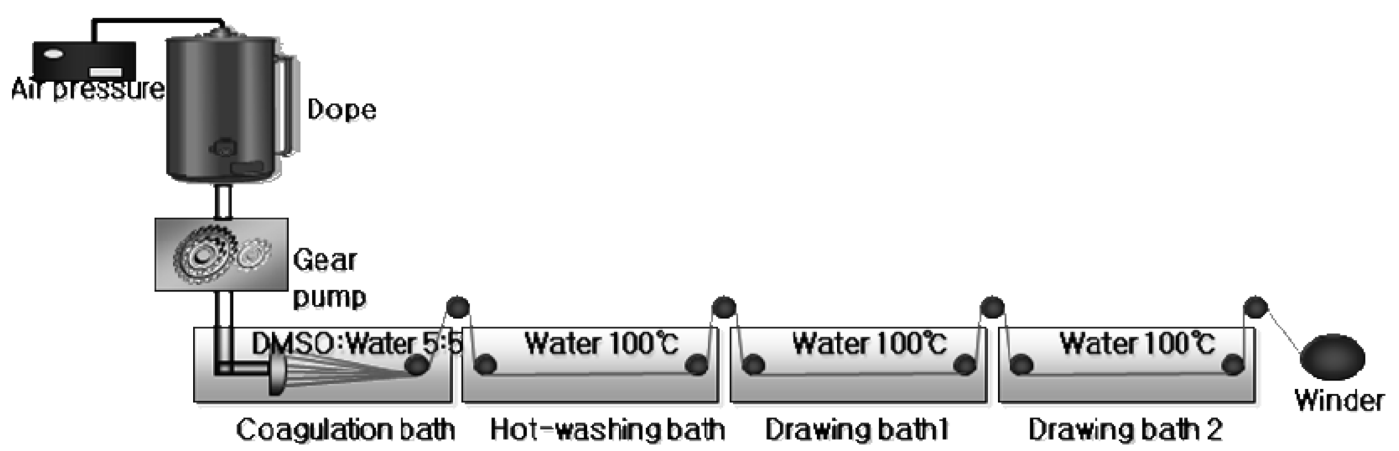

Fig. 1. A schematic of a lab scale wet spinning line for polyacrylonitrile fibers.

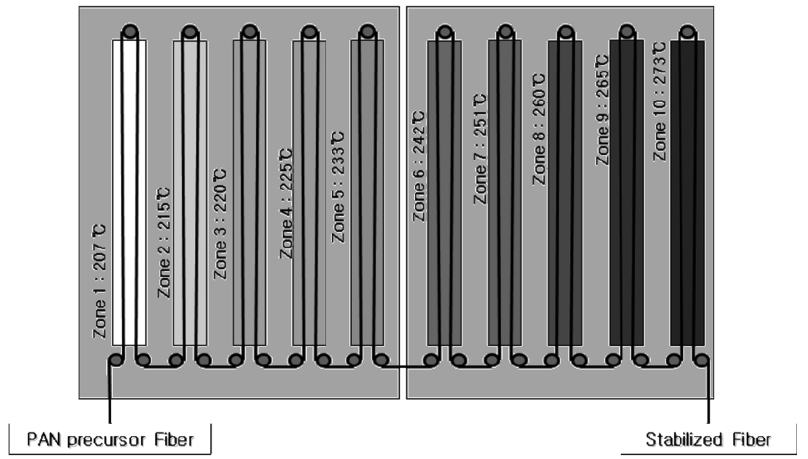

Fig. 2. A schematic of a continuous tailor-made stabilization system for polyacrylonitril fibers.

convection oven for 2 days at $60^{\circ} \mathrm{C}$.

Spun fibers were stabilized using continuous tailor-made stabilization system with ten columns, where fibers were passed through with a tension (Fig. 2). Each column has a different stabilization temperature. A total stabilization time varied $(45,65$, and $110 \mathrm{~min})$ with controlling a passing speed of fibers. Furthermore, temperature profile was changed with a constant total stabilization time of $65 \mathrm{~min}$. Maximum set temperature at the last column varied from 234 to $273^{\circ} \mathrm{C}$. Carbonization of stabilized fibers under nitrogen atmosphere was performed using a tubular furnace (Korea Furnace Development Co. Ltd, Korea) without tension. A purity of nitrogen gas was $99.999 \%$. After fiber loading, the temperature increased to a set point of $1200^{\circ} \mathrm{C}$ at a rate of $5^{\circ} \mathrm{C} / \mathrm{min}$, and fibers were cooled down without hold. For a yield calculation, fibers weighted before and after carbonization, and the yield was $45-50 \%$.

Fourier transform infrared (FTIR) spectra of spun PAN and its stabilized fibers were obtained using a Nicolet iS10 FTIR spectrometer (Thermo Scientific, USA) in a range of $400-4000 \mathrm{~cm}^{-1}$ with an attenuated total reflectance mode. For mechanical testing, a single fiber was loaded to a paper tab with a $25 \mathrm{~mm}$ gauge length. An epoxy resin was applied to both ends of fibers, and cured for $24 \mathrm{~h}$ at $60^{\circ} \mathrm{C}$. Fiber diameters were measured by a scanning electron microscope (SEM; Hitachi FE S-4800, Japan). The tensile properties were determined using an Instron Universal Tester 5567 (Instron, USA) at $25^{\circ} \mathrm{C}$. The crosshead speed was $5 \mathrm{~mm} / \mathrm{min}$ for all specimens, and twenty replicates were tested at each condition. Cross-sections of PAN and CFs were observed using an optical microscope (Olympus BX51, Japan) and the SEM, respectively.

\section{Results and Discussion}

\subsection{Fiber spinning}

Fiber spinning was conducted with a lab scale spinning system shown in Fig. 1. A drawing speed through the coagulation bath varied from 1 to $3 \mathrm{~m} / \mathrm{min}$, which affected drawing speed in the washing baths significantly. A maximum drawing speed after the final washing bath was $8 \mathrm{~m} / \mathrm{min}$ when the drawing speed through the coagulation bath was $1 \mathrm{~m} / \mathrm{min}$. The maximum speed increased to 10 and $13 \mathrm{~m} / \mathrm{min}$ in the final washing bath with the fibers spun in the coagulation bath with a drawing speed of 2 and $3 \mathrm{~m} / \mathrm{min}$, respectively. This is a consequence of an amount of remaining DMSO after diffused into the coagulation bath. As expected, the drawn fibers with a higher speed in the coagulation bath have shorter residence time in the coagulation bath, and a higher amount of remaining DMSO, which leads to more stretching in the following washing baths.

Spun fibers were stabilized using a continuous stabilization system with ten columns. The first column was at $207^{\circ} \mathrm{C}$, and temperature increased by $5-10^{\circ} \mathrm{C}$ in following columns. The temperature of the final column was $273^{\circ} \mathrm{C}$. A total stabilization time was $65 \mathrm{~min}$ with applying tension to fibers. Stabilized fibers were carbonized in a furnace at $1200^{\circ} \mathrm{C}$ without tension. Fig. 3 shows tensile strength and modulus of CFs. CFs experienced the drawing speed of $1 \mathrm{~m} / \mathrm{min}$ during wet spinning showed higher tensile properties than those with the drawing speed of $2 \mathrm{~m} / \mathrm{min}$ did. A further decrease of tensile properties was observed with $\mathrm{CFs}$ experienced the drawing speed of $3 \mathrm{~m} / \mathrm{min}$. A morphological study was performed to understand property-structure relationship. 


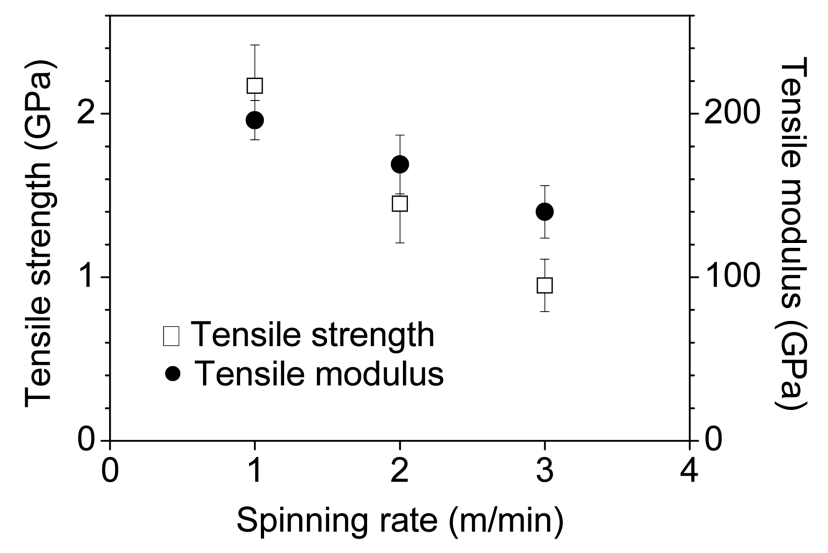

Fig. 3. Tensile properties of carbon fibers as a function of a drawing speed in the coagulation bath.
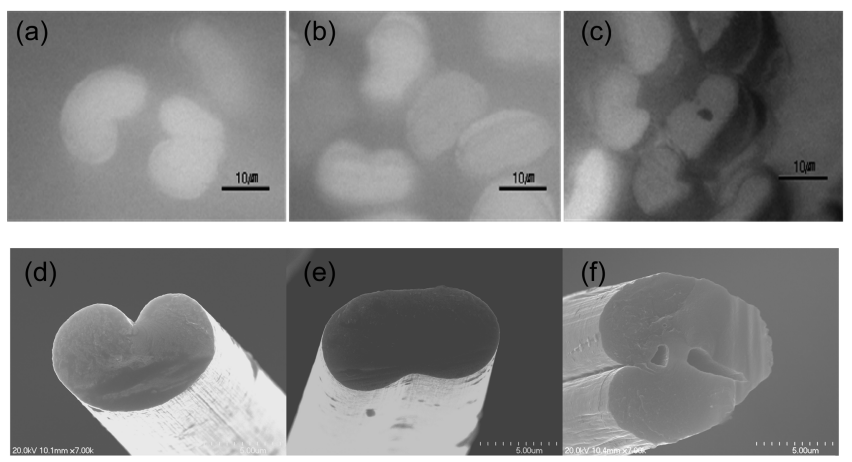

Fig. 4. Optical microscope images of polyacrylonitril spun fibers with a drawing speed of (a) $1 \mathrm{~m} / \mathrm{min}$, (b) $2 \mathrm{~m} / \mathrm{min}$, and (c) $3 \mathrm{~m} / \mathrm{min}$ in the coagulation bath, and scanning electron microscopy images of their carbon fibers with a drawing speed of (d) $1 \mathrm{~m} / \mathrm{min}$, (e) $2 \mathrm{~m} / \mathrm{min}$, and (f) $3 \mathrm{~m} / \mathrm{min}$.

Cross-sections of PAN fibers were observed using an optical microscope (Olympus BX51, Japan) in Figs. 4(a-c). Figs. 4(a) and (b) showed a kidney or bean-shaped cross section of PAN fibers experienced the drawing speed of 1 and $2 \mathrm{~m} / \mathrm{min}$ in the coagulation bath, respectively. PAN fibers experienced the drawing speed of $3 \mathrm{~m} / \mathrm{min}$ have significant voids inside (Fig. $4 \mathrm{c}$ ). When residence time is not long enough for solvent in fibers to diffuse out in coagulation bath, an unstable skin is developed. Hence, the remaining solvent diffuses out rigorously in washing bath, which contains only distillated water. In washing bath, water can diffuse into fiber though the unstable skin. It is known that when diffusion is so fast not to develop a solid skin, voids are observed, resulting from water diffusion into fibers [1]. SEM images of CFs are displayed in Figs. 4(d-f), which are carbonized fibers of PAN fibers shown in Figs. 4(a-c), respectively. It is obvious that diameter of CFs is smaller than that of PAN fibers. Figs. 4(d) and (e) show a beanshaped and CFs in Fig. 4(c) have significant voids inside. It is recalled that CFs experienced the drawing speed of $3 \mathrm{~m} / \mathrm{min}$ showed low tensile strength and modulus. From optical microscope and SEM images of PAN and CFs, it is evident that structural defects, such as voids, result in decrease of tensile properties. Furthermore, this indicates that there is an optimal drawing condition to achieve the high performance CFs.

\subsection{Stabilization}

Another major step for preparing CFs is stabilization. As expected, stabilization time and temperature are key factors to obtain high tensile properties of CFs. Our tailor-made stabilization system can control a total stabilization time and temperature profile using passing speed of fibers and separately controlled heating unit on ten columns, respectively (Fig. 2). For studying the effect of stabilization time on tensile properties of CFs, spun fibers with the drawing speed of $1 \mathrm{~m} / \mathrm{min}$ in coagulation bath were used, and three stabilized fibers were prepared with a total stabilization time of 45,65 , or $110 \mathrm{~min}$. For temperature profiles, the first column was at $207^{\circ} \mathrm{C}$ and temperature increased by $5-9^{\circ} \mathrm{C}$ in following columns. The temperature of the last column was $273^{\circ} \mathrm{C}$. The detail temperature of each column was in Fig. 1.

Fig. 5 shows FTIR spectra of PAN and its stabilized fibers with the continuous tailor-made stabilization system. Before stabilization, distinct absorption bands appeared at 2939, $2243,1720,1454,1360$, and $785 \mathrm{~cm}^{-1}$ assigned to $v_{\mathrm{C}-\mathrm{H}}$ in $\mathrm{CH}_{2}, v_{\mathrm{C} \equiv \mathrm{N}}$ in $\mathrm{CN}, v_{\mathrm{C}=\mathrm{O}}$ in $\mathrm{COOH}, \delta_{\mathrm{C}-\mathrm{H}}$ in $\mathrm{CH}_{2}, \delta_{\mathrm{C}-\mathrm{H}}$ in $\mathrm{CH}$, and $\delta_{\mathrm{C}-\mathrm{C}}$ in $\mathrm{C}-\mathrm{CN}$, respectively (Fig. 5(a)). The band at $1720 \mathrm{~cm}^{-1}$ is due to itaconic acid modified in PAN as a comonomer, while other bands are associated with PAN. Stabilized fibers for $45 \mathrm{~min}$ showed an appearance at

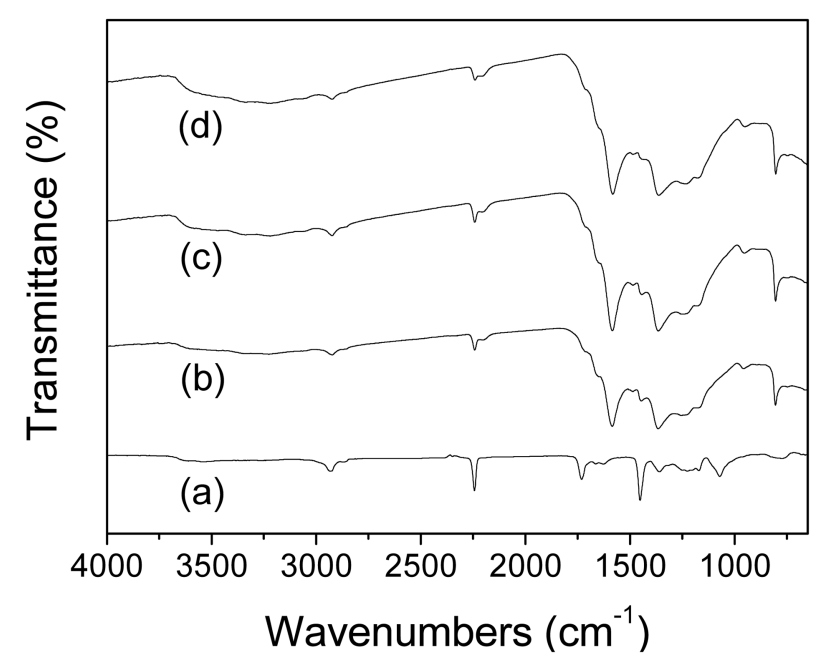

Fig. 5. Fourier transform infrared spectra of (a) polyacrylonitril fiber and its stabilized fibers at $208-275^{\circ} \mathrm{C}$ for: (b) $45 \mathrm{~min}$, (c) $60 \mathrm{~min}$, and(d) $110 \mathrm{~min}$ 


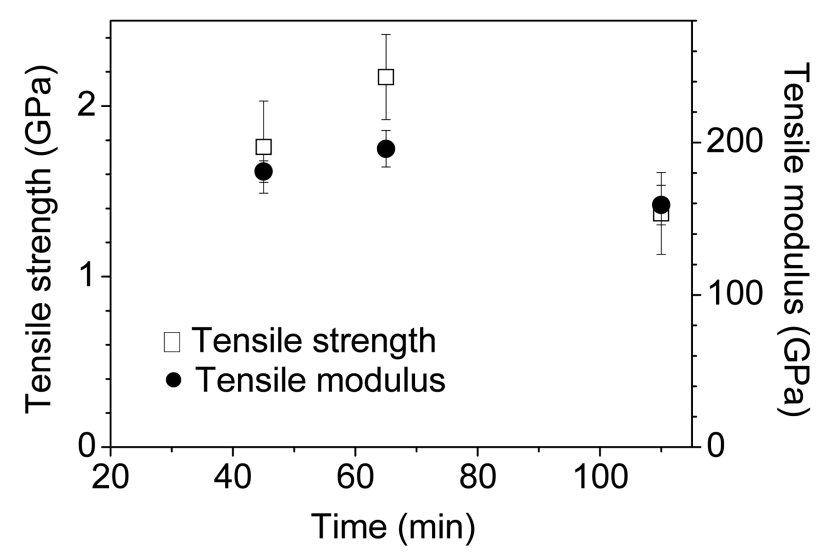

Fig. 6. Tensile properties of carbon fibers as a function of a total stabilization time at $208-275^{\circ} \mathrm{C}$.

$1595 \mathrm{~cm}^{-1}$ assigned to conjugated $\mathrm{C}=\mathrm{N}$ stretching with a strong intensity, and bands at 2243 and $1454 \mathrm{~cm}^{-1}$ significantly decreased, resulting from the cyclization and dehydrogenation of fibers (Fig. 5(b)). The very small band at $1720 \mathrm{~cm}^{-1}$ was observed, which indicates that most itaconic acids participated in cyclization reaction through an ionic mechanism.

Additional changes in FTIR spectrum were observed at a wavelength of 2200, 1710 and $1660 \mathrm{~cm}^{-1}$ (Fig. 5(b)). Two shoulders appeared at 1710 and $1660 \mathrm{~cm}^{-1}$. Shimada et al. [7] reported that these shoulders are assigned to the free ketones in hydronaphthyridine rings and the conjugated ketones in acridone rings, resulting from the oxygen uptake reaction. A new distinct band at $2200 \mathrm{~cm}^{-1}$ was observed with stabilized fibers. It is reported that the band is assigned to the $\alpha, \beta$ unsaturated nitrile groups due to hydrogenation, or tautomerization and isomerisation of the ladder polymer $[8,9]$. A similar change was observed with the fibers stabilized for 65 or $110 \mathrm{~min}$. It is likely that FTIR spectroscopy is not sensitive enough to distinguish the degree of cyclization of stabilized fiber for 45,65 , or $110 \mathrm{~min}$.

Carbonization was conducted at $1200^{\circ} \mathrm{C}$ without tension. Fig. 6 displays tensile properties of CFs. Tensile strengths were $1.8 \pm 0.2,2.2 \pm 0.2$, and $1.4 \pm 0.2 \mathrm{GPa}$ with $\mathrm{CFs}$ stabilized for 45,65 , and $110 \mathrm{~min}$, respectively. CFs stabilized for

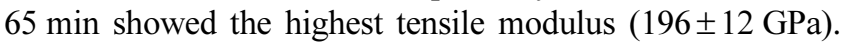
It is evident that tensile properties of CFs depend on stabilization time significantly. During stabilization process, cyclization of the nitrile groups, dehydration of saturated carbon-carbon bond, and oxidation occurred, resulting in an increase of density [10]. It was found that densities of stabilized fibers for 45, 65, and 110 min were 1.308, 1.327, and $1.360 \mathrm{~g} / \mathrm{cm}$, respectively. As expected, a longer stabilization time showed a higher density. It is interesting that CFs from the highest density stabilized fibers did not show the highest tensile strength.

For studying the effect of stabilization temperature on

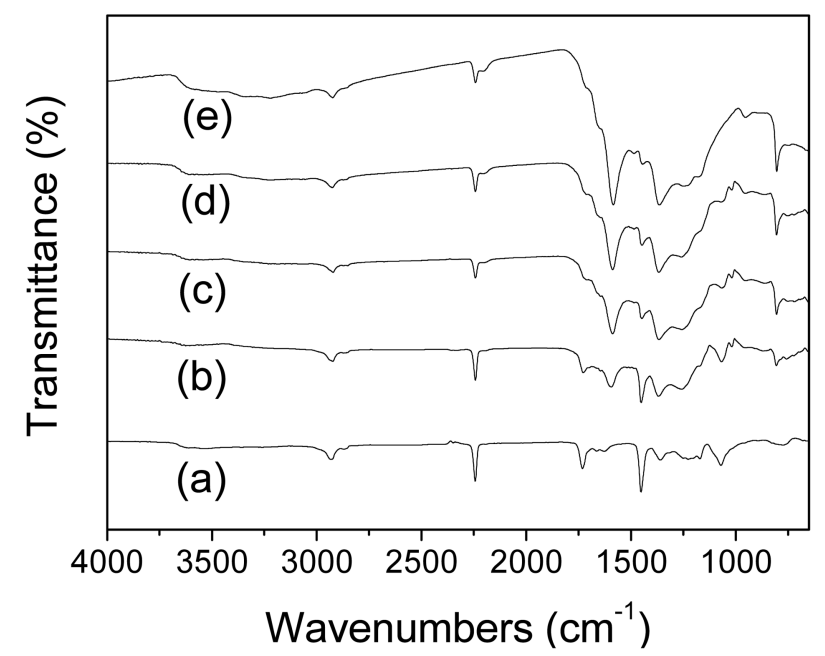

Fig. 7. Fourier transform infrared spectra of (a) polyacrylonitril fiber and its stabilized fibers for $60 \mathrm{~min}$ at: (b) $166-234^{\circ} \mathrm{C}$ (c) $180-247^{\circ} \mathrm{C}$, (d) $193-260^{\circ} \mathrm{C}$, and (e) $207-273^{\circ} \mathrm{C}$.

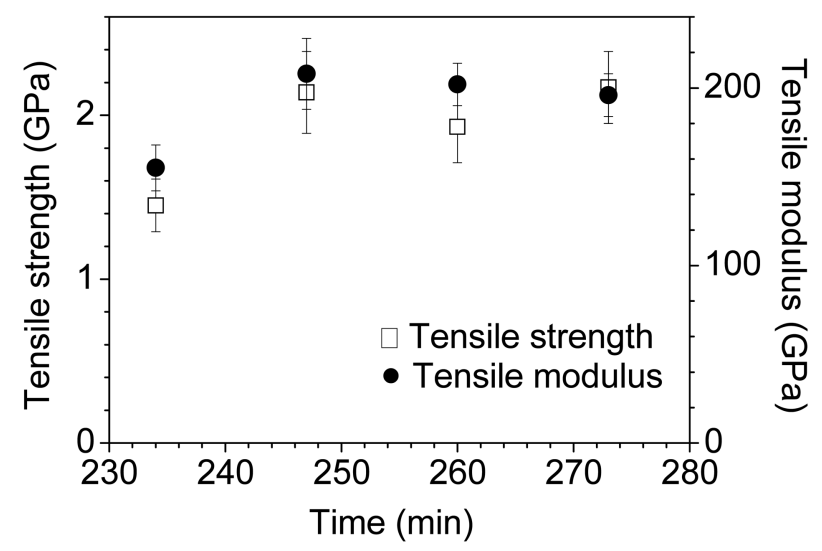

Fig. 8. Tensile properties of carbon fibers as a function of stabilization temperature profile for $65 \mathrm{~min}$. The abscissa axis represents stabilization temperature of the last column.

tensile properties of CFs, spun fibers with the drawing speed of $1 \mathrm{~m} / \mathrm{min}$ in coagulation bath were stabilized with various temperature profiles for a given total stabilization time of $65 \mathrm{~min}$. For the highest temperature profile, the first and last columns were at $207^{\circ} \mathrm{C}$ and $273^{\circ} \mathrm{C}$, respectively. Three more different temperature profiles were used to prepare stabilized fibers. Temperatures of all columns were decreased down by 15,30 , or $45^{\circ} \mathrm{C}$. Therefore, four different temperature profiles were used for stabilization: $166-234^{\circ} \mathrm{C}, 180-247^{\circ} \mathrm{C}, 193-$ $260^{\circ} \mathrm{C}$, or $207-273^{\circ} \mathrm{C}$. For this work, fibers are designated by the last column temperature as L234, L247, L260, and $\mathrm{L} 273^{\circ} \mathrm{C}$, respectively.

Fig. 7 shows FTIR spectra of PAN and its stabilized fibers with different temperature profile. It was observed that FTIR spectra of L247 and L260 are similar to that of L273. However, in FTIR spectrum of L234, an absorption band 
was observed at $1454 \mathrm{~cm}^{-1}$, which is due to itaconic acid in PAN as a comonomer. This reveals that fibers have remaining itaconic acid for a more reaction. Furthermore, a smaller intensity of a band at $1595 \mathrm{~cm}^{-1}$, assigned to conjugated $\mathrm{C}=\mathrm{N}$ stretching, in $\mathrm{L} 234$ than that in other stabilized fibers indicates a lower degree of stabilization for L234 fibers.

These fibers were carbonized at $1200^{\circ} \mathrm{C}$ without tension. Fig. 8 displays tensile properties of resulting CFs. Tensile strengths after carbonization with L234, L247, L260, and $\mathrm{L} 273$ were $1.5 \pm 0.2,2.1 \pm 0.2,1.9 \pm 0.2$, and $2.2 \pm 0.2 \mathrm{GPa}$, respectively. As expected, tensile strength is the lowest for L230 fibers. However, there was no significant difference among other fibers. It is evident that stabilization temperature with a given system is of importance for tensile properties of CFs. It was found that densities of stabilized fibers for L234, L247, L260, and L273 were 1.264, 1.295, 1.311 , and $1.327 \mathrm{~g} / \mathrm{cm}$, respectively. Even though a higher stabilization temperature resulted in higher density, CFs from the stabilized fibers with highest density did not show the highest tensile strength. This is similar to the effect of stabilization time on tensile strength.

\section{Conclusions}

PAN based CF were prepared using a lab scale wet spinning line, a continuous tailor-made stabilization system, and a batch type carbonization furnace. A wet spinning speed, related with diffusion rate of solvent in PAN dope, was significant in morphology of PAN spun and CFs. Even though a high spinning speed led to a high stretching of spun fibers, significant voids in the spun and CFs resulted in low tensile strength and modulus of CFs. The effect of stabilization time and temperature profile on CFs was also investigated. A longer total stabilization time with a given temperature profile $\left(207\right.$ to $\left.273^{\circ} \mathrm{C}\right)$ resulted in a higher fiber density. However, CFs stabilized for $65 \mathrm{~min}$ showed higher tensile strength and modulus. Furthermore, there was significant effect of stabilization temperature on tensile properties. These results indicate that effects of spinning rate, stabilization time, and temperature profile on tensile strength and modulus were significant, and an optimal stabilization condition is necessary to enhance tensile properties of CFs.

\section{Acknowledgements}

This work was supported by a grant from Korea Institute of Science and Technology Institutional program and the Fundamental R\&D Program for Core Technology of Materials funded by the Ministry of Knowledge Economy, Republic of Korea.

\section{References}

[1] Baojun Q, Ding P, Zhenqiou W. Adv Polym Tech, 6, 509 (1986).

[2] Ying L, Hou C, Fei W. J Appl Polym Sci, 100, 4447 (2006).

[3] Hou C, Qu R, Wang C, Ying L. J Appl Polym Sci, 101, 3616 (2006).

[4] Fitzer E, Frohs W, Heine M. Carbon, 24, 387 (1986).

[5] Kim J, Kim YC, Ahn W, Kim CY. Polym Eng Sci, 33, 1452 (1993).

[6] Yamane A, Sawai D, Kameda T, Kanamoto T, Ito M, Porter RS. Macromolecules, 30, 4170 (1997).

[7] Shimada I, Takahagi T, Fukuhara M, Morita K, Ishitani A. J Polym Sci, Part A: Polym Chem, 24, 1989 (1986).

[8] Dalton S, Heatley F, Budd PM. Polymer, 40, 5531 (1999).

[9] Xue TJ, McKinney MA, Wilkie CA. Polym Degrad Stab, 58, 193 (1997).

[10] Buckley JD, Edie DD. Carbon-Carbon Materials and Composites, NASA Reference Publication 1254, National Aeronautics and Space Administration, Washington, DC (1992). 